\title{
Scintillation and Dosimeter Properties of $\mathrm{LiAlSi}_{2} \mathrm{O}_{6}$ and $\mathrm{LiAlSi}_{4} \mathrm{O}_{10}$ Crystals
}

\author{
Takayuki Yanagida, ${ }^{*}$ Yutaka Fujimoto, ${ }^{1}$ Masanori Koshimizu, ${ }^{1}$ \\ Narumi Kumamoto, Go Okada, and Noriaki Kawaguchi \\ Nara Institute of Science and Technology, 8916-5 Takayama, Ikoma, Nara 630-0192, Japan \\ ${ }^{1}$ Department of Applied Chemistry, Graduate School of Engineering, Tohoku University, \\ 6-6-07 Aoba, Aramaki, Aoba, Sendai, Miyagi 980-8579, Japan \\ (Received February 11, 2017; accepted July 13, 2017)
}

Keywords: scintillator, TSL, OSL, mineral, $\mathrm{LiAlSi}_{2} \mathrm{O}_{6}, \mathrm{LiAlSi}_{4} \mathrm{O}_{10}$

Optical, scintillation, optically stimulated luminescence, and thermally stimulated luminescence properties of nondoped $\mathrm{LiAlSi}_{2} \mathrm{O}_{6}$ and $\mathrm{LiAlSi}_{4} \mathrm{O}_{10}$ mineral crystals were investigated. The photoluminescence emission wavelengths of $\mathrm{LiAlSi}_{2} \mathrm{O}_{6}$ and $\mathrm{LiAlSi}_{4} \mathrm{O}_{10}$ were 300-500 and 350-600 nm, respectively, and the scintillation emission wavelengths were similar. Under vacuum ultraviolet photon excitation at a synchrotron facility (UVSOR), excitation bands of $\mathrm{LiAlSi}_{2} \mathrm{O}_{6}$ and $\mathrm{LiAlSi}_{4} \mathrm{O}_{10}$ appeared at around 150 and $180 \mathrm{~nm}$, respectively. The decay lifetime of $\mathrm{LiAlSi}_{2} \mathrm{O}_{6}$ was on the nanosecond order while that of $\mathrm{LiAlSi}_{4} \mathrm{O}_{10}$ was on the millisecond order for both photoluminescence and scintillation. Both samples showed thermally stimulated luminescence, and $\mathrm{LiAlSi}_{4} \mathrm{O}_{10}$ had a higher sensitivity. When we investigated optically stimulated luminescence, $\mathrm{LiAlSi}_{4} \mathrm{O}_{10}$ exhibited a detectable signal, while we could not observe a signal in $\mathrm{LiAlSi}_{2} \mathrm{O}_{6}$.

\section{Introduction}

Solid-state luminescent materials have played an important role in ionizing radiation detectors since they have a high detection efficiency for high-energy photons such as X-and $\gamma$-rays. These luminescent materials are mainly categorized into two types, namely, a scintillator, which converts the absorbed energy of ionizing radiation into numerous low-energy photons immediately, and a storage phosphor, which accumulates radiation energy and releases it in the form of luminescence under some stimulations. The latter type of detectors are called dosimeters, which are used for monitoring the radiation dose absorbed by individuals and environmental radiation. Although these detectors are commonly used to measure ionizing radiation, scintillators and dosimeters have been studied in different scientific fields since the measurement techniques are largely different. Recently, we have noted that scintillation- and ionizing-radiation-induced storage luminescence properties show a complementary relationship in some materials; ${ }^{(1,2)}$ thus, it is important to study both properties in one material in order to understand the ionizing-radiation-induced luminescence properties of solid-state materials.

In this study, we focus on $\mathrm{LiAlSi}_{2} \mathrm{O}_{6}$ and $\mathrm{LiAlSi}_{4} \mathrm{O}_{10}$. As scintillation detectors, they can be used as thermal neutron detectors since they contain $\mathrm{Li}$ in their chemical composition. Owing to

*Corresponding author: e-mail: t-yanagida@ms.naist.jp

http://dx.doi.org/10.18494/SAM.2017.1619 
the limited ${ }^{3} \mathrm{He}$ gas supply, ${ }^{(3,4)}$ much effort has been made to develop novel scintillators for neutron detection. Generally, light scintillators including ${ }^{6} \mathrm{Li}$ or ${ }^{10} \mathrm{~B}$ elements are preferred for neutron detectors to avoid detecting background $\gamma$-ray signals. ${ }^{(5)}$ From this point of view, $\mathrm{LiAlSi}_{2} \mathrm{O}_{6}$ and $\mathrm{LiAlSi}_{4} \mathrm{O}_{10}$ may preferably be used for neutron detection. On the other hand, in dosimeter applications, light materials are commonly used, especially in individual radiation monitoring applications. In the ideal case, if the effective atomic number of the detector material is the same as that of the human soft tissue, no mathematical corrections are required to determine the exposure dose. Therefore, these two materials, $\mathrm{LiAlSi}_{2} \mathrm{O}_{6}$ and $\mathrm{LiAlSi}_{4} \mathrm{O}_{10}$, are interesting for solidstate ionizing detector applications.

$\mathrm{LiAlSi}_{2} \mathrm{O}_{6}$ and $\mathrm{LiAlSi}_{4} \mathrm{O}_{10}$ are known as kunzite and petalite in mineralogy, respectively. These materials have been mainly studied as ionic conductive materials. ${ }^{(6)}$ Sometimes, the former was studied for optically stimulated luminescence $\left(\mathrm{OSL}^{(7)}\right)$ or thermally stimulated luminescence (TSL $^{(8)}$ ) dosimeter applications. ${ }^{(9-11)}$ On the other hand, there have been no reports on the luminescence properties of $\mathrm{LiAlSi}_{4} \mathrm{O}_{10}$. Recently, it has been confirmed that highly sensitive detection performance can be achieved by doping some impurities as luminescence centers, ${ }^{(12)}$ and it is highly important to understand the luminescence properties of the undoped sample in order to develop efficient scintillator and dosimeter materials. Therefore, in this study, we have studied optical, scintillation, and dosimeter properties of nominally undoped bulk $\mathrm{LiAlSi}_{2} \mathrm{O}_{6}$ and $\mathrm{LiAlSi}_{4} \mathrm{O}_{10}$ crystals.

\section{Experimental Procedure}

The sample crystals were colorless natural minerals. A photograph of the samples used here is presented in Fig. 1. The samples were cut from bulk minerals and their wide surfaces were polished for optical characterization.

In-line optical transmittance spectra were evaluated using a JASCO V670 spectrometer in the wavelength range from 190 to $2700 \mathrm{~nm}$ with $1 \mathrm{~nm}$ intervals. To evaluate basic photoluminescence (PL) properties, PL spectra and decay time profiles were measured with a Hamamatsu Quantaurus- $\tau$ (Hamamatsu). The excitation and monitoring wavelengths for $\mathrm{LiAlSi}_{2} \mathrm{O}_{6}$ were 280 and $400 \mathrm{~nm}$, respectively. In the case of $\mathrm{LiAlSi}_{4} \mathrm{O}_{10}$, the excitation and monitoring wavelengths were 340 and $420 \mathrm{~nm}$, respectively. In our instrument, seven LEDs with different emission wavelengths were installed. From these seven LEDs, we selected those with a suitable wavelength for the measurement. After these basic optical characterizations, excitation spectra at vacuum ultraviolet (VUV) wavelengths were observed at a synchrotron facility, ultraviolet synchrotron orbital radiation (UVSOR). The monitoring wavelengths were the same as those in PL decay measurements, and excitation spectra from 50 to $200 \mathrm{~nm}$ were observed.

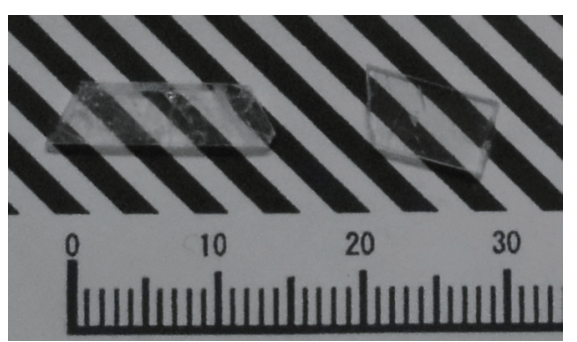

Fig. 1. (Color online) Photograph of $\mathrm{LiAlSi}_{2} \mathrm{O}_{6}$ (left) and $\mathrm{LiAlSi}_{4} \mathrm{O}_{10}$ (right) crystals. 
For ionizing-radiation-induced luminescence properties, basic scintillation properties such as X-ray-induced radioluminescence (RL) spectra $^{(13)}$ and decay time profiles ${ }^{(14)}$ were first investigated using the original setup. The supplied bias voltage and tube current for the RL spectra were $40 \mathrm{kV}$ and $5.2 \mathrm{~mA}$, respectively. Furthermore, dosimeter properties including OSL and TSL were investigated. The radiation source used was an X-ray generator, and the irradiation dose was calibrated using an ionization chamber (TN30013, PTW). After 1 Gy X-ray exposure, OSL emission and stimulation spectra were collected using a spectrofluorometer (FP8600, JASCO). TSL properties were evaluated using a Nano-gray TL2000. The detailed descriptions of the TSL evaluations can be found in our previous work. ${ }^{(15)}$ The irradiation dose was varied from 0.01 to 10 Gy, and the heating rate was $1^{\circ} \mathrm{C} / \mathrm{s}$.

\section{Results and Discussion}

Figure 2 shows the transmittance spectra of the two crystals. No particular absorption bands were detected; thus, we assumed that no significant contamination of transition metals (TMs) or rare-earth (RE) ions was present. Although no reports could be found for the bandgap energies of these materials, the absorption edge measured for the $\mathrm{LiAlSi}_{2} \mathrm{O}_{6}$ sample (210-250 nm from Fig. 2) was consistent with the numerical calculation, ${ }^{(16)}$ which suggested a value of $5.5 \mathrm{eV}(\sim 220 \mathrm{~nm})$. In the case of $\mathrm{LiAlSi}_{4} \mathrm{O}_{10}$, the bandgap could be in the VUV region since we could not measure the entire absorption edge in the measurable spectral region of the instrument.

PL emission spectra of $\mathrm{LiAlSi}_{2} \mathrm{O}_{6}$ and $\mathrm{LiAlSi}_{4} \mathrm{O}_{10}$ are demonstrated in Fig. 3. The emission of $\mathrm{LiAlSi}_{2} \mathrm{O}_{6}$ appeared at around 350 and $450 \mathrm{~nm}$, while that of $\mathrm{LiAlSi}_{4} \mathrm{O}_{10}$ was observed at $420 \mathrm{~nm}$. Note that the excitation sources used were 280 and $340 \mathrm{~nm}$ LEDs, which have Gaussian-like emission spectra with a full width at half maximum (FWHM) of $\sim 40 \mathrm{~nm}$. Therefore, in the case of $\mathrm{LiAlSi}_{2} \mathrm{O}_{6}$, the tail of the excitation spectrum overlapped with the bandgap. The spectral shapes were very broad; thus, the origin of the emission should be the $\mathrm{d}-\mathrm{d}$ transitions of some TMs, the $\mathrm{d}-\mathrm{f}$ transitions of RE ions, $\mathrm{ns}^{2}$ ions, or some defects or excitons. Thus, we further investigated optical properties to consider the possible origin. From the transmittance, most RE ions can

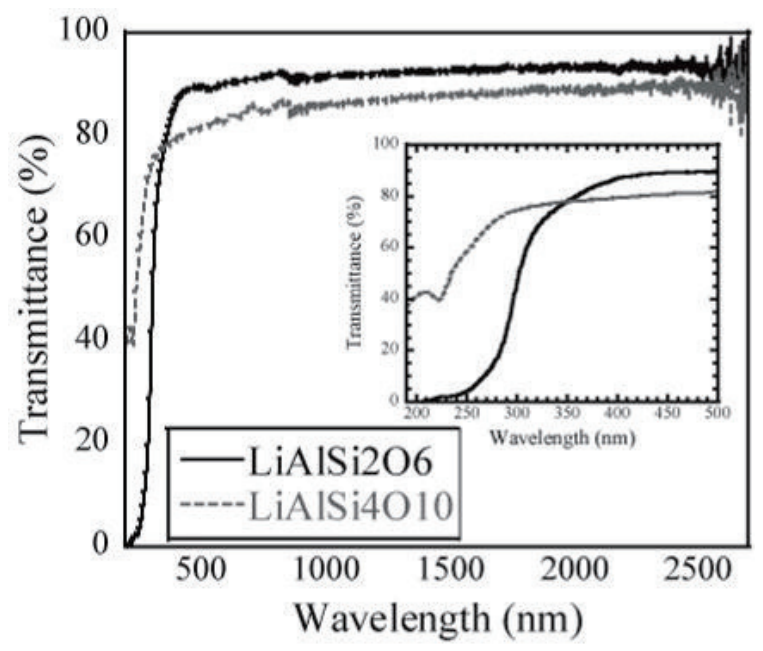

Fig. 2. Transmittance spectra of $\mathrm{LiAlSi}_{2} \mathrm{O}_{6}$ and $\mathrm{LiAlSi}_{4} \mathrm{O}_{10}$ crystals. The inset expands the data from 190 to 500 $\mathrm{nm}$. 


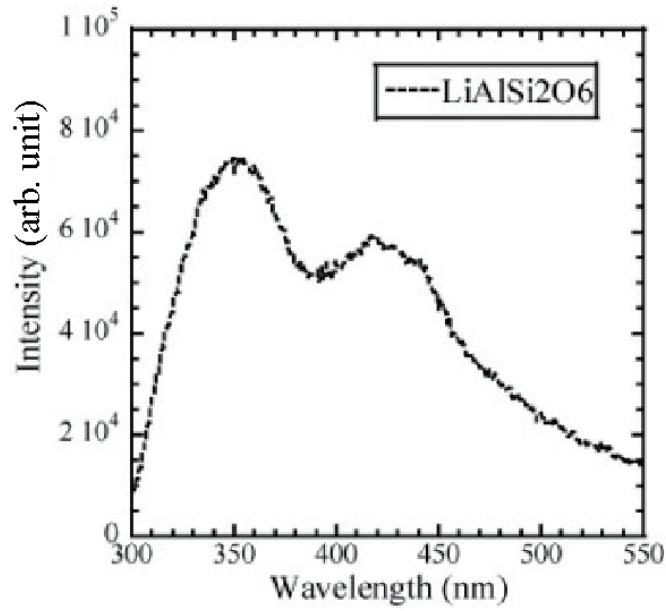

(a)

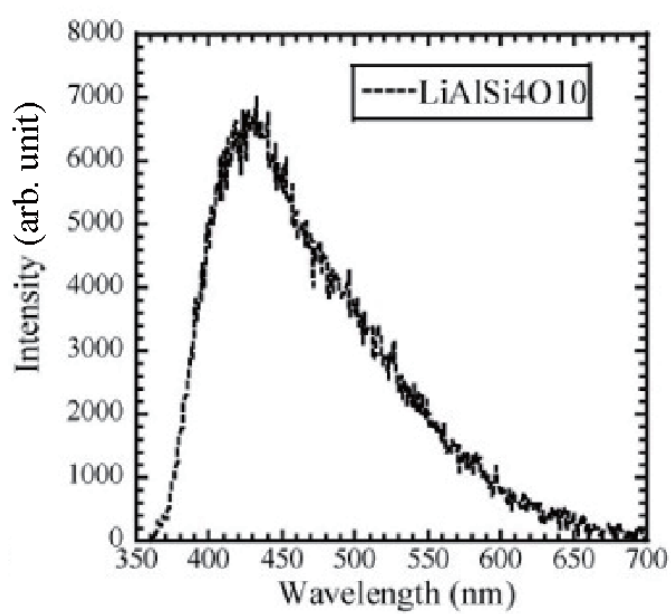

(b)

Fig. 3. PL spectra of (a) $\mathrm{LiAlSi}_{2} \mathrm{O}_{6}$ under $280 \mathrm{~nm}$ excitation and (b) $\mathrm{LiAlSi}_{4} \mathrm{O}_{10}$ under $340 \mathrm{~nm}$ excitation.

be dismissed since the absorption for $\mathrm{d}-\mathrm{f}$ radiative transitions generally appears as a broad and intense absorption band in ultraviolet or visible wavelength ranges, and such an absorption band was not observed at all. If the absorption at $220 \mathrm{~nm}$ observed in $\mathrm{LiAlSi}_{2} \mathrm{O}_{6}$ were due to $\mathrm{RE}$ ions, the remaining possibilities would be $\mathrm{Ce}^{3+}$ or $\mathrm{Pr}^{3+}$. In the case of $\mathrm{Ce}^{3+}$, generally absorption bands appear at longer wavelengths in oxide materials, so the contamination of $\mathrm{Ce}^{3+}$ is not likely the origin. In the case of $\mathrm{Pr}^{3+}$, some sharp lines due to the $4 \mathrm{f}-4 \mathrm{f}$ transitions must also be observed together with a broad emission of the $5 \mathrm{~d}-4 \mathrm{f}$ transitions; however, no such sharp lines were observed. For these reasons, the origins of the emissions observed in these crystals cannot be the contamination of RE ions based on the transmittance and PL spectra.

Figure 4 shows PL decay curves of these crystals. The PL decay time of $\mathrm{LiAlSi}_{2} \mathrm{O}_{6}$ was 5.9 $\mathrm{ns}$, while that of $\mathrm{LiAlSi}_{4} \mathrm{O}_{10}$ was $4 \mathrm{~ms}$. In $\mathrm{LiAlSi}_{2} \mathrm{O}_{6}, \mathrm{TMs}$ and $\mathrm{ns}^{2}$ ions were considered unlikely to be the origins since they showed decay times on the order of $\mu \mathrm{s}-\mathrm{ms}$. Therefore, the emission origin of $\mathrm{LiAlSi}_{2} \mathrm{O}_{6}$ could be some defects or excitons. On the other hand, in $\mathrm{LiAlSi}_{4} \mathrm{O}_{10}$, at least the possibility of $\mathrm{ns}^{2}$ ions is neglected since their typical decay time is several tens to hundreds of microseconds. Thus, a possible emission origin could be some TMs (e.g., $\mathrm{Mn}^{2+}$ ), defects, or excitons.

To further investigate the emission origin, the VUV excitation spectra measured at UVSOR are shown in Fig. 5. In $\mathrm{LiAlSi}_{2} \mathrm{O}_{6}$, an excitation band appeared at around $150 \mathrm{~nm}$, which is shorter than that corresponding to the bandgap energy. Generally, excitation bands caused by emission centers such as dopant impurities and defect centers appear within the bandgap. Thus, a possible emission origin of $\mathrm{LiAlSi}_{2} \mathrm{O}_{6}$ could be excitons, and the most plausible origin is self-trapped excitons. In the previous work, the emission origin of the nondoped $\mathrm{LiAlSi}_{2} \mathrm{O}_{6}$ was considered to be the radiative recombination of an electron with a hole trapped by a defect site in which the $\mathrm{Al}^{3+}$ ion substituted for the $\mathrm{Si}^{4+}$ ion (Al center). ${ }^{(9)}$ However, in such a case, excitation bands must exist within the bandgap. In contrast, there have been no observations or theoretical works on the bandgap of $\mathrm{LiAlSi}_{4} \mathrm{O}_{10}$, and we cannot discuss this conclusively. Considering that this material consists of the same elements as $\mathrm{LiAlSi}_{2} \mathrm{O}_{6}$, and typical oxide materials show bandgaps at around $160-220 \mathrm{~nm}$, the excitation peak at around $175 \mathrm{~nm}$ should be around the bandgap. If this peak is the band gap, the possibility of TM contamination is at least eliminated since the excitation due to 


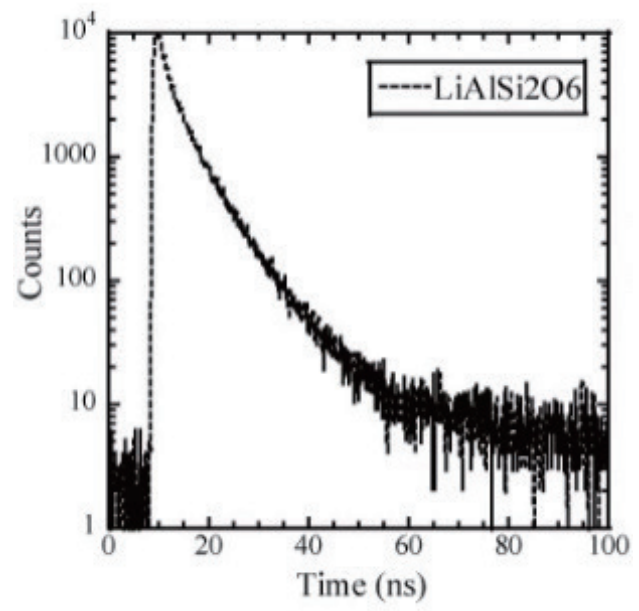

(a)

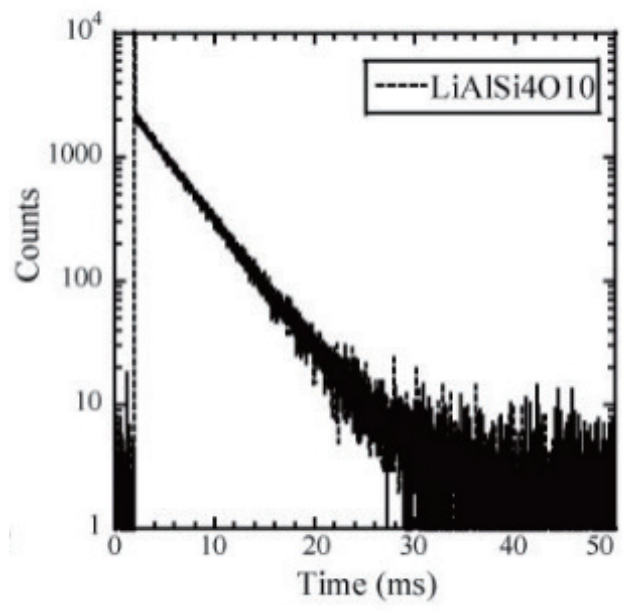

(b)

Fig. 4. PL decay time profiles of (a) $\mathrm{LiAlSi}_{2} \mathrm{O}_{6}$ and (b) $\mathrm{LiAlSi}_{4} \mathrm{O}_{10}$.

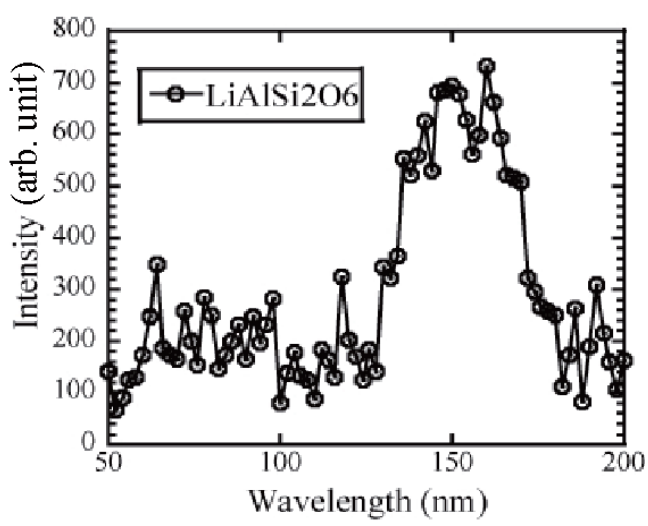

(a)

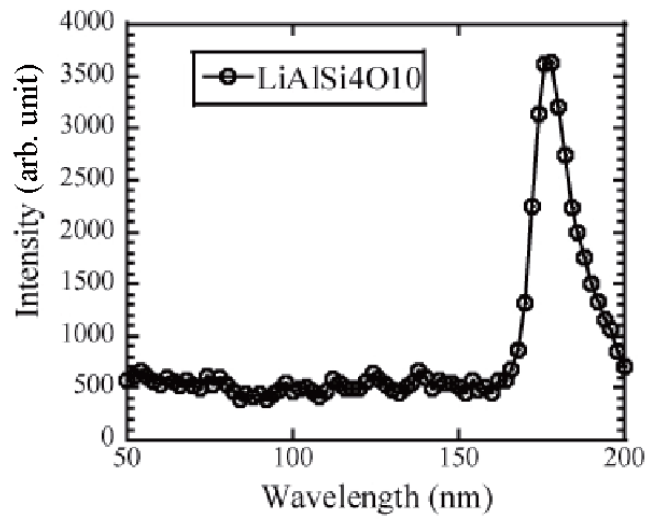

(b)

Fig. 5. PL excitation spectra of (a) $\mathrm{LiAlSi}_{2} \mathrm{O}_{6}$ at monitoring wavelengths of 300-500 $\mathrm{nm}$ and (b) $\mathrm{LiAlSi}_{4} \mathrm{O}_{10}$ at $350-550 \mathrm{~nm}$ in VUV wavelengths measured in UVSOR.

TMs typically appears within the bandgap. Generally, exciton-based luminescence is fast, but it is sometimes on the order of microseconds in the slowest case. Therefore, a possible emission origin of $\mathrm{LiAlSi}_{4} \mathrm{O}_{10}$ could be the triplet excited states in some defects.

Figure 6 shows X-ray-induced scintillation spectra. Emission wavelengths of $\mathrm{LiAlSi}_{2} \mathrm{O}_{6}$ and $\mathrm{LiAlSi}_{4} \mathrm{O}_{10}$ are consistent with those in PL spectra (Fig. 3). The emission at around $600 \mathrm{~nm}$ in $\mathrm{LiAlSi}_{2} \mathrm{O}_{6}$ is a second-harmonic diffraction of the emission peak at around $300 \mathrm{~nm}$ since we could not detect this peak in PL under various excitation wavelengths. Although this evaluation is not a quantitative analysis, the emission intensity of $\mathrm{LiAlSi}_{4} \mathrm{O}_{10}$ was very low compared with that of $\mathrm{LiAlSi}_{2} \mathrm{O}_{6}$. In neutron detectors, the energy deposited is typically $4.8 \mathrm{MeV}$ in ${ }^{6} \mathrm{Li}$-containing materials based on the ${ }^{6} \mathrm{Li}(n, \alpha)^{3} \mathrm{H}$ reaction, and a higher emission intensity can be expected.

Figure 7 shows scintillation decay time profiles of $\mathrm{LiAlSi}_{2} \mathrm{O}_{6}$ and $\mathrm{LiAlSi}_{4} \mathrm{O}_{10}$. The decay curves were approximated by a single exponential decay function. As a result, the decay times 


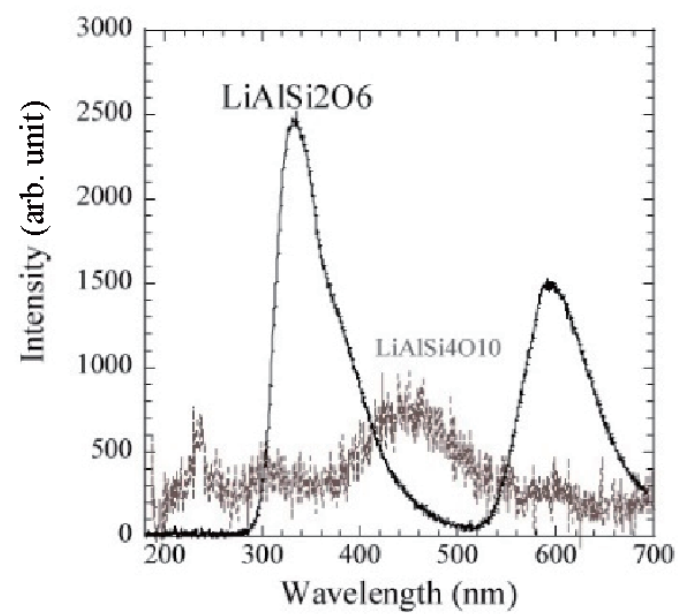

Fig. 6. X-ray-induced scintillation spectra of $\mathrm{LiAlSi}_{2} \mathrm{O}_{6}$ and $\mathrm{LiAlSi}_{4} \mathrm{O}_{10}$.

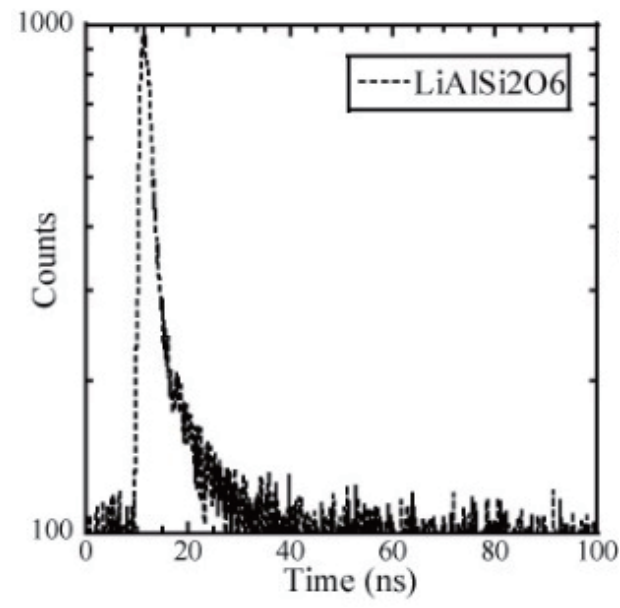

(a)

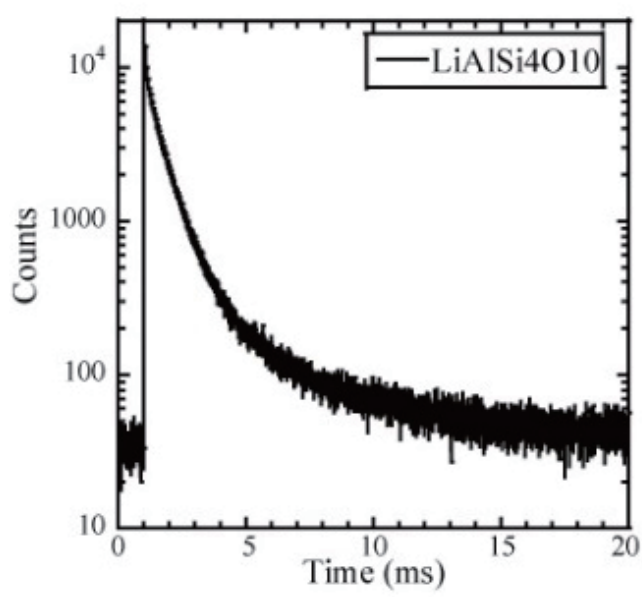

(b)

Fig. 7. X-ray-induced scintillation decay time profiles of (a) $\mathrm{LiAlSi}_{2} \mathrm{O}_{6}$ and (b) $\mathrm{LiAlSi}_{4} \mathrm{O}_{10}$.

of $\mathrm{LiAlSi}_{2} \mathrm{O}_{6}$ and $\mathrm{LiAlSi}_{4} \mathrm{O}_{10}$ were $10.8 \mathrm{~ns}$ and $1.9 \mathrm{~ms}$, respectively. The timing resolution of the instrument was a few nanoseconds; thus, the decay curve of $\mathrm{LiAlSi}_{2} \mathrm{O}_{6}$ may be partially affected by the instrumental response. Compared with PL decay times, the observed values were consistent.

OSL emission and stimulation spectra of $\mathrm{LiAlSi}_{4} \mathrm{O}_{10}$ are depicted in Fig. 8. Although the signal intensity was low, OSL appeared at around $420 \mathrm{~nm}$ under $550 \mathrm{~nm}$ stimulation. On the other hand, we could not observe a clear OSL signal from $\mathrm{LiAlSi}_{2} \mathrm{O}_{6}$. Previous studies reported OSL from $\mathrm{LiAlSi}_{2} \mathrm{O}_{6}$ mixed with Teflon after X-ray irradiations of several hundred grays or higher. ${ }^{(10)}$ Thus, if the irradiation dose increases, an OSL signal may be detected in this bulk crystal sample.

TSL glow curves of $\mathrm{LiAlSi}_{2} \mathrm{O}_{6}$ and $\mathrm{LiAlSi}_{4} \mathrm{O}_{10}$ after $10 \mathrm{~Gy}$ exposure are demonstrated in Fig. 9. In TSL measurement, glow peaks were clearly detected at $100{ }^{\circ} \mathrm{C}$ in $\mathrm{LiAlSi}_{2} \mathrm{O}_{6}$ and at $200{ }^{\circ} \mathrm{C}$ in $\mathrm{LiAlSi}_{4} \mathrm{O}_{10}$. Although there have been no reports about nondoped $\mathrm{LiAlSi}_{4} \mathrm{O}_{10}$, the TSL of Teflonmixed ${ }^{(11)}$ and natural mineral ${ }^{(9)}$ samples of $\mathrm{LiAlSi}_{2} \mathrm{O}_{6}$ was investigated and a glow peak was 


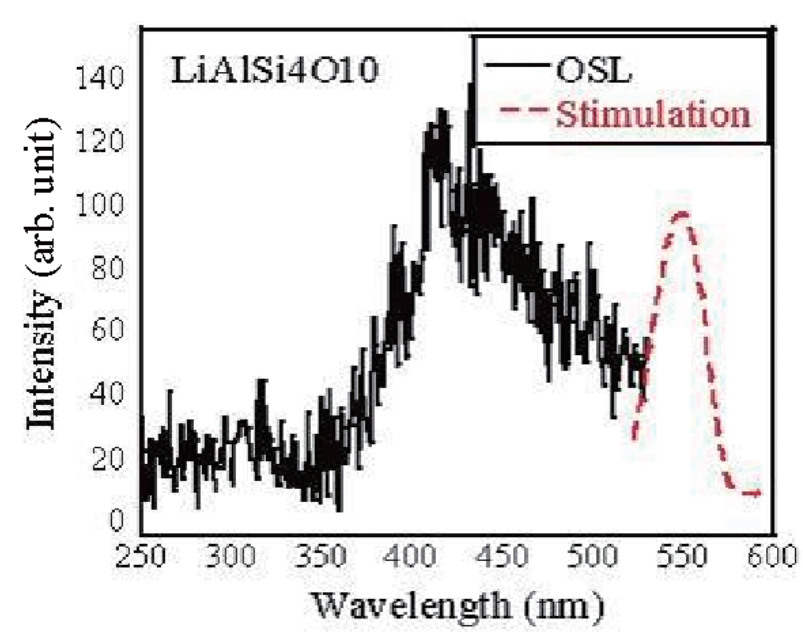

Fig. 8. (Color online) OSL and stimulation spectra of $\mathrm{LiAlSi}_{4} \mathrm{O}_{10}$ after 1 Gy exposure.

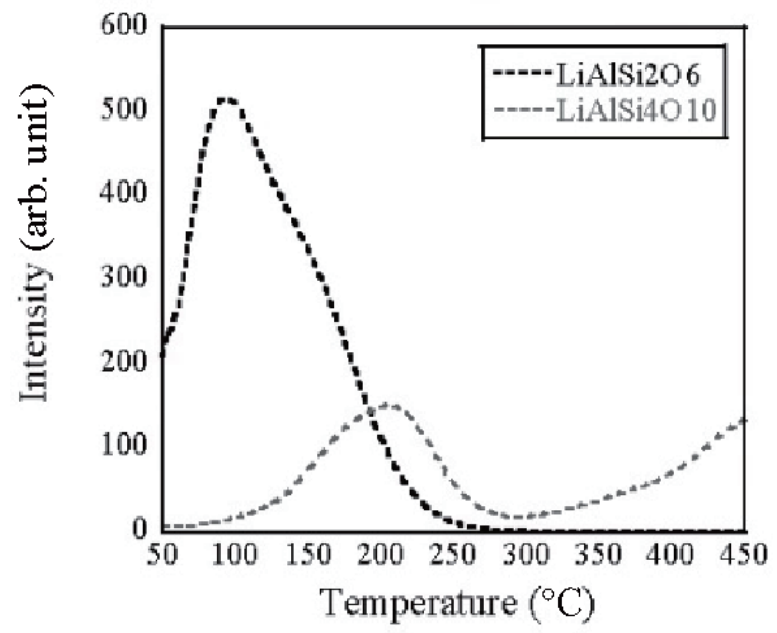

Fig. 9. TSL glow curves of $\mathrm{LiAlSi}_{2} \mathrm{O}_{6}$ and $\mathrm{LiAlSi}_{4} \mathrm{O}_{10}$ after $10 \mathrm{~Gy}$ exposure.

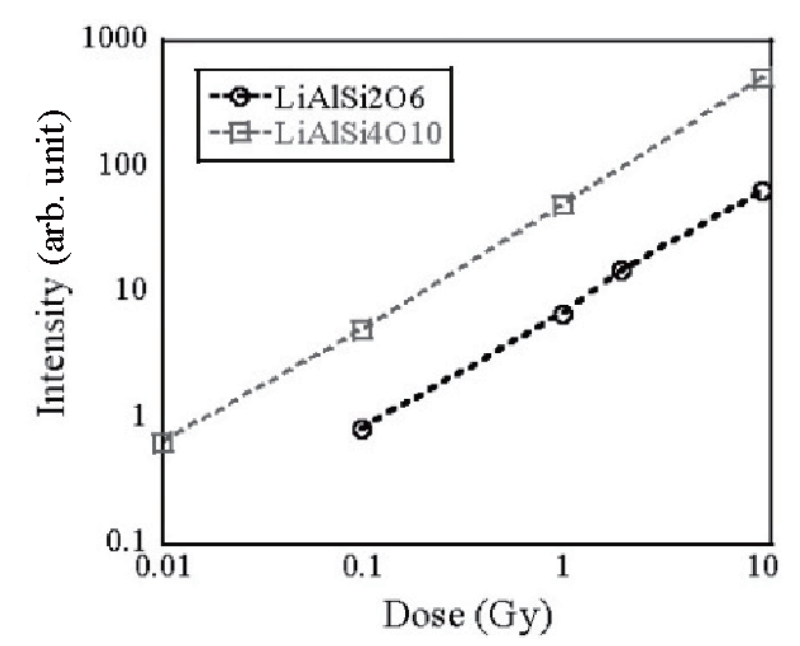

Fig. 10. TSL dose response functions of $\mathrm{LiAlSi}_{2} \mathrm{O}_{6}$ and $\mathrm{LiAlSi}_{4} \mathrm{O}_{10}$.

observed at $150-200{ }^{\circ} \mathrm{C}$. The variation in glow peak temperature could be due to the mixture (Teflon) or synthetic routes of samples.

Figure 10 shows dose response functions of $\mathrm{LiAlSi}_{2} \mathrm{O}_{6}$ and $\mathrm{LiAlSi}_{4} \mathrm{O}_{10}$ crystals. The linear response from $10 \mathrm{mGy}$ to $10 \mathrm{~Gy}$ was confirmed in $\mathrm{LiAlSi}_{4} \mathrm{O}_{10}$, while that of $\mathrm{LiAlSi}_{2} \mathrm{O}_{6}$ was observed from $100 \mathrm{mGy}$ to $10 \mathrm{~Gy}$. In previous works on $\mathrm{LiAlSi}_{2} \mathrm{O}_{6}$, TSL signals were evaluated at high doses from several tens to kilogray order ${ }^{(9-11)}$ in both TSL and OSL. The present work opens a new possibility of using $\mathrm{LiAlSi}_{2} \mathrm{O}_{6}$ to detect low doses. In addition, the present work shows the high potential of $\mathrm{LiAlSi}_{4} \mathrm{O}_{10}$ for dosimeter applications since the present sample was a nominally nondoped sample. Generally, doped materials are used in practical dosimeter applications to enhance the sensitivity, and by doping several emission centers, a higher sensitivity can be expected in $\mathrm{LiAlSi}_{4} \mathrm{O}_{10}$. 


\section{Conclusions}

$\mathrm{LiAlSi}_{2} \mathrm{O}_{6}$ and $\mathrm{LiAlSi}_{4} \mathrm{O}_{10}$ mineral crystals were examined in terms of their optical, scintillation, and dosimeter properties. The former showed emissions at 300-500 nm for both PL and scintillation, while the latter showed emissions at $420 \mathrm{~nm}$ for PL, scintillation, and OSL. When TSL properties were evaluated, $\mathrm{LiAlSi}_{4} \mathrm{O}_{10}$ showed a better performance, and a linear response from 10 mGy to 10 Gy was confirmed.

\section{Acknowledgments}

This work was supported by a Grant-in-Aid for Scientific Research (A) 17H01375 from the Ministry of Education, Culture, Sports, Science and Technology of Japan (MEXT) and partially by JST A-step. The Cooperative Research Project of the Research Institute of Electronics, Shizuoka University, is also acknowledged.

\section{References}

1 T. Yanagida, Y. Fujimoto, K. Watanabe, K. Fukuda, N. Kawaguchi, Y. Miyamoto, and H. Nanto: Radiat. Meas. 71 (2014) 162.

2 T. Yanagida: J. Lumin. 169 (2016) 544.

3 R. T. Kouzes: Technical Rep. PNNL-18388, Pacific Northwest National Laboratory (2009).

4 R. T. Kouzes, J. H. Ely, A. T. K. Lintereur, E. D. Mace, L. Stephens, and M. L. Woodring: Nucl. Instrum. Methods Phys. Res., Sect. A 654 (2012) 412.

5 K. Watanabe, T. Yanagida, K. Fukuda, A. Koike, T. Aoki, and A. Uritani: Sens. Mater. 27 (2015) 269.

6 A. Welsch, H. Behrens, S. Ross, and D. Murawski: Z. Phys. Chem. 226 (2012) 491.

7 S. W. S. McKeever: Radiat. Meas. 46 (2011) 1336.

8 S. W. S. McKeever: Thermoluminescence of Solids (Cambridge University Press, New York, 1985).

9 G. M. Ferraz, J. R. B. Paião, S. Watanabe, and S. O. Souza: Radiat. Meas. 43 (2008) 387.

10 R. A. P. O. d'Amorim, D. A. A. de Vasconcelos, V. S. M. de Barros, H. J. Khoury, and S. O. Souza: Radiat. Phys. Chem. 95 (2014) 141.

11 R. A. P. O. d'Amorim, M. I. Teixeira, S. O. Souza, J. M. Sasaki, and L. V. E. Caldas: J. Lumin. 132 (2012) 266.

12 T. Yanagida: Opt. Mater. 35 (2013) 1987.

13 T. Yanagida, K. Kamada, Y. Fujimoto, H. Yagi, and T. Yanagitani: Opt. Mater. 35 (2013) 2480.

14 T. Yanagida, Y. Fujimoto, T. Ito, K. Uchiyama, and K. Mori: Appl. Phys. Express 7 (2014) 062401.

15 T. Yanagida, Y. Fujimoto, N. Kawaguchi, and S. Yanagida: J. Ceram. Soc. Jpn. 121 (2013) 988.

16 A. F. de Lima, S. O. Souza, and M. V. Lalic: Opt. Mater. 30 (2007) 1048. 